\title{
An improved HIV care cascade to assess HIV control programs among people who inject drugs.
}

Jean-Pierre Molès ( $\square$ jean-pierre.moles@inserm.fr )

INSERM https://orcid.org/0000-0002-6863-6350

Marianne Peries

INSERM

Duong Thi Huong

Hai Phong Medical University

Truong Thi Xuan Lien

Institut Pasteur d' Ho Chi Minh City

Roselyne Vallo

INSERM

Aurélie Barrail-Tran

INSERM U1177 Drugs and Molecules for Living Systems

Hoang Thi Giang

Hai Phong Medical University

Nham Thi Tuyet Thanh

SCDI

Pham Minh Khue

Hai Phong Medical University

Vu Hai Vinh

Viet tiep Hospital

Kamyar Arasteh

New York University

Delphine Rapoud

INSERM

Catherine Quillet

INSERM

Jonathan Feelemyer

New York University

Laurent Michel

French Red Cross

Khuat Thi Hai Oanh

SCDI

Don Des Jarlais 
New York University

Didier Laureillard

INSERM

Nicolas Nagot

INSERM

\section{Research article}

Keywords: Persons who inject drugs, cascade of care, HIV, peer community group, lamivudine, Vietnam Posted Date: December 4th, 2019

DOI: https://doi.org/10.21203/rs.2.18178/v1

License: (a) This work is licensed under a Creative Commons Attribution 4.0 International License. Read Full License 


\section{Abstract}

Background Achievement of HIV control among key populations through universal access to antiretroviral treatment (ART) requires a precise evaluation of the cascade of care. One of the main difficulties in obtaining an accurate community-based cascade of care is misreporting, which could represent one of the most important bias for people suffering from stigma. The primary objective was to estimate the added value of plasma antiretroviral concentration to improve the estimation of HIV cascade of care

Methods We constructed the cascade of HIV care among persons who inject drugs (PWID) living in Hai Phong, Vietnam, using a community-based survey. First and second line HIV treatment contained fixed dose of lamivudine. Misreporting of HIV status and ART were identified by plasma lamivudine detection. We then compared the two methods for estimating the cascade of HIV care

Results The proportion of misreporting was estimated at 30\% among PWID. No specific PWID profile could be identified as associated with misreporting.

Conclusions Adding plasma ARV detection to the routine data collection strongly improved the accuracy of the HIV cascade of care.

\section{Background}

Controlling HIV transmission among key populations is a key component of national programs in countries with non-generalized epidemics. In many low and middle income countries, people who inject drugs (PWID) represent the main key population. Although harm reduction, including access to sterile needles and syringes and medication assisted therapy, proved effective in controlling HIV among PWID [1], large scale antiretroviral treatment (ART) can accelerate the elimination of HIV transmission among this group [2-4]. However, this engagement in care is complicated by stigma, centering on drug and poor economic status [5-9]. The obstacles are numerous and vary along the cascade of care: confidentiality issues regarding HIV testing, stigma in health care centers, administrative issues (ID cards lost or pawned), out-of-pocket money for HIV care, high rates of mental health issues and ART dropout during incarceration. Given these obstacles, it is critical to assess the performance of HIV care programs in order to identify gaps and propose adaptive strategies. Estimating the cascade of care among PWID utilizes the ' $90-90-90$ ' target [10], whereby more than 70\% of all HIV-infected PWID in a population are under successful ART. However, obtaining precise metrics of the various steps of this cascade remain a challenge. Wrong estimates, leading to mis-specified gaps and inadequate correction of interventions can divert limited resources where they are not needed. If the last " 90 " evaluation is factual i.e. having a controlled viral load or not, the first " 90 " requires an accurate estimation of the population size which remains challenging when addressing PWID [11]. The second "90" relies on self-declaration. Two approaches are classically used to estimate this part of the HIV cascade of care, either based on data from HIV care centers or from a sample of the PWID population using questionnaires, HIV testing and HIV viral load $[12,13]$. Neither of these approaches is satisfactory: data from the health care system are 
objective and usually accurate but often do not report PWID status [14], while population-based estimates often rely on participant declarations with limitations such as misreporting of HIV status or ART use [15]. Combining both is theoretically possible but would require very large resources.

We hypothesize that objective metrics of care performance including the assay of plasma ARV can help estimate the level of misreporting, and, when possible, can help correct misreporting from populationbased surveys.

In this report, we estimate the added value of plasma lamivudine concentration, a surrogate marker of HIV care, to improve the estimation of a population-based HIV cascade of care in Hai Phong city, Vietnam.

\section{Methods}

\section{Study Design:}

We implemented a cross-sectional survey among PWID using a respondent driven sampling (RDS) approach in order to compare two methods for estimating the cascade of HIV care; one based on the results of self-report of HIV care, and the second based on an objective marker of HIV care. For the latter, we selected the detection of lamivudine in plasma because this drug composed both the first line and the second-line of HIV treatment in Vietnam at the time of the study.

\section{Study implementation and flow:}

We recruited 'active' PWID using an RDS survey in Hai Phong, Vietnam, during September and October 2014, using the following inclusion criteria: (i) reporting injection drug use and having recent skin marks of injection, (ii) having drug detected in urine (heroin or methamphetamine) and (iii) able and willing to provide informed consent. Details of the RDS survey have been described elsewhere $[2,16]$. The study took place in a community setting, in the office of a major peer support group of the city. A standardized questionnaire was administered by a trained interviewer selected from three community support groups. This questionnaire addressed issues on participant's drug use, sexual behaviors, medical and administration-related events (arrests, etc.). A venous sample was taken by a nurse on site for HIV testing (Determine $^{\mathrm{TM}} \mathrm{HIV}-1 / 2$, Alere ${ }^{\mathrm{TM}}$, Waltham, USA) and plasma biobanking. Participants returned to the study site one week later for their HIV test result confirmation which was done at the provincial AIDS center laboratory. HIV viral load was measured on the banked blood sample at the national reference laboratory (NIHE, Hanoi) using the COBAS Taqman HIV-1 test v2.0 (Roche diagnostics, Hanoi, Vietnam).

\section{Plasma lamivudine (3TC) quantification:}


After alcaline extraction from stored plasma sampled, lamivudine was detected using high pressure liquid chromatography with ultraviolet detection as previously described [17]. The lower limit of detection of the assay was set at $25 \mathrm{ng} / \mathrm{ml}$ of plasma, lower than $40 \mathrm{ng} / \mathrm{ml}$, the mean trough concentration at steady state before once daily lamivudine intake (300mg).

\section{Data Collection \& data analyses:}

All data were collected through electronic CRF using Ennov Clinical ${ }^{\circledR}$ software.

Baseline characteristics of participants were presented using number and percentage for categorical data; and median and interquartile range (IQR) for quantitative variables.

The usual cascade of care was constructed as follows: the denominator was all HIV-infected PWID, selfdeclaration was used to estimate the proportion of HIV-infected PWID aware of their HIV status, and of those with efficacious ART defined by a plasma viral load $<1,000$ copies $/ \mathrm{mL}$ as per WHO recommendations [18].

For the construction of the improved cascade, we assumed that HIV-infected PWID with detectable lamivudine in plasma were aware of their HIV status, whatever their responses to the questionnaire.

All statistical analyses were done with SAS software (Version 9.4; Copyright@ 2016, SAS Institute Inc., Cary, NC, USA).

\section{Results}

\section{Study population characteristics}

During the 5 weeks of RDS, we recruited 603 PWID, including 152 (25.2\%) HIV-infected PWID. The PWID were mainly male, with a median age of 37 years, and $25 \%$ had a national health insurance card. The HIV positive and HIV negative PWID differed from age, having a child, having illegal incomes and being incarcerated (Table 1).

\section{Cascades of HIV care}

Out of 150 HIV seropositive participants with a HIV viral load and a plasma lamivudine available result, 85 (56.7\%) reported they knew their HIV-positive status. Among the remaining 65, 39 said that had never been tested and 1 declined to answer. Out of the 25 who said "have ever been tested for HIV", 13 reported a negative HIV result and 12 did not share the result of their last test. 
The overall performance of this standard cascade (Fig 1.) shows a major gap in HIV testing with only $56.7 \%$ of HIV-infected participants reporting their HIV positive status. The following steps were satisfactory, though they did not reach the $90 / 90$ target.

The revised cascade of care, built with the lamivudine plasma detection, had a very different shape. Twenty seven participants who did not report their HIV seropositivity had detectable lamivudine in plasma. The proportion of participants aware of their HIV+ status increased to $74 \%$ (no PrEP was available at the time), $94 \%$ of the patients were under ART but the percentage of virological success was reduced from 82 to 72 .

During the questionnaire, 13 (48.2\%) of the 27 participants who misreported "having not been tested previously", 7 had a negative HIV test result during their last visit, and 6 did not answer. When analyzing their characteristics, this population shared the same profile to the population having disclosed their HIV seropositivity with the exception of their marital status (Table 2).

\section{Discussion}

Accurate performance indicators of the HIV cascade of care need to be constantly improved and adapted to the target population [19]. Routine questionnaires are frequently biased by misreporting behavior leading to an often inappropriate evaluation of the HIV care performance [7, 9]. Herein, we report that i) this misreporting is significant among PWID, leading to a biased estimate of the cascade of care, and ii) this bias can be corrected by adding plasma dosage of a quasi-universal ART (lamivudine) when elaborating the cascade.

The identification of individuals with detectable ARV in plasma increased the number of PWID aware of their HIV seropositivity by $30 \%$. In this stigmatized group, the fear of discrimination and lack of trust towards health care workers could certainly be driving some of the misreporting. However, poor understanding of HIV care from PWID may have also played a role [20]. To overcome these difficulties, it was suggested that: (i) questionnaires could be administrated by peers, (ii) and run outside the health service system and (iii) data should come from population-based surveys [15]. While we fulfilled all these conditions, we observed that the accuracy of the cascade of care was still suboptimal. Combining plasma ARV detection to self-declaration is necessary to accurately construct the cascade of care. Currently, the detection of ARV requires techniques and expertise that is often only available at national level laboratories. Although the availability of HPLC represents an obstacle to scaling-up improved cascade of care, current research is aimed at developing rapid tests to detect ARV in order to document and assist treatment adherence. So far, these tests are mostly designed to detect tenofovir ${ }^{\circledR}$ [21-23]. These tests could then be repositioned for epidemiological purposes, to accurately evaluate the cascade of care.

Misreporting of HIV status by PWID was reported previously [24]. In Vietnam, a qualitative study investigated the cognitive and motivational biases of HIV risk behaviors among drug users [25], but did not address HIV testing self-report. Recently, studies evaluated the level of such discrepancies among 
HIV-positive adults not using drugs in South Africa. Using the same design, i.e. comparing selfdeclaration of HIV testing and plasma ARV detection, they found that the level of discrepancies ranged from $18 \%$ to $41 \%[20,26]$. Among the factors associated with misreporting, they identified "being a man" as a positive risk. Our study population is overwhelmingly male, so we could not test for this risk.

Our study has several limitations. Some patients may have been on an ART that did not contain lamivudine. According to several HIV clinicians in the city, the prevalence was below $1 \%$, as the second line regimen contained lopinavir/r, lamivudine and tenofovir. We could not adequately assess the role of data entry errors in the rate of misreporting, but it is likely very low as built-in consistency checks were in place in the eCRF.

Of note, the $30 \%$ underreporting bias for HIV status awareness is likely an underestimation as it does not account for those participants who did not disclose their HIV status but who are not currently on ART. The proportion of the latter is certainly not negligible (encompassing those never treated and those who dropped from ART) but impossible to estimate using objective tools.

\section{Conclusions}

Among populations suffering from stigma such as PWID, the estimation of population-based cascade of HIV care is prone to substantial misreporting bias, which can be misleading for the allocation of resources and interventions. Adding plasma ARV detection such as lamivudine can partly correct this bias.

\section{List Of Abbreviations}

ART: antiretroviral treatment

ARV: antiretroviral

eCRF: electronic case report form

HPLC: high pressure liquid chromatography

IQR: interquartile range

PrEP: pre-exposure prophylaxis

PWID: people who inject drug

RDS: reposndent driven sampling

WHO: world health organisation

\section{Declarations}


Ethics approval and conset to participate: The study was reviewed and approved by the Institutional Review Boards of the Hai Phong University of Medicine and Pharmacy (Vietnam) and the Icahn School of Medicine at Mount Sinai (USA). It is registered in www.clinicaltrials.gov (NCT02573948).

\section{Consent for publication: not applicable}

Availability of data and materials: The datasets generated and/or analysed during the current study are not publicly available but are available from the corresponding author on reasonable request. In that case, deidentified individual participant data (including data dictionaries) will be made available.

Competing interests: The authors declare that they have no competing interests

Funding: This work was supported by grants \#12299 and \#P30DA011041 from the French "Agence Nationale de Recherche sur le SIDA et hépatite virale" (ANRS) and US National Institute of Drug Abuse (NIDA), respectively.

Authors' contributions: Study design: JPM, NN; formal analysis: TTXL, ABT, RV, MP, KA; data curation: JPM, RV, MP; writing (original draft preparation): JPM, NN, DL; writing (review and editing): JF, DDJ, VVH, LM; supervision: PMK, NTTT, DR; project administration: HTG, CQ, JF; funding acquisition: DDJ, NN, HDT, HOKT.

Acknowledgements: We want to specifically acknowledge Dr. Vu Van Cong, Dr. Anne-Marie Taburet, and Pr. F. Barré-Sinoussi (ANRS Vietnam site coordinators) for their help at the early stage of the project and their inestimable advices. Finally, we thank all the participants enrolled in the study.

\section{Reference}

1. Larney S, Peacock A, Leung J, Colledge S, Hickman M, Vickerman P, et al. Global, regional, and country-level coverage of interventions to prevent and manage HIV and hepatitis $\mathrm{C}$ among people who inject drugs: a systematic review. Lancet Glob Health. 2017;5:e1208-20.

2. Des Jarlais D, Duong HT, Pham Minh K, Khuat OHT, Nham TTT, Arasteh K, et al. Integrated respondent-driven sampling and peer support for persons who inject drugs in Haiphong, Vietnam: a case study with implications for interventions. AIDS Care. 2016;28:1312-5.

3. Jarlais DCD, Duong HT. Ending HIV epidemics among people who inject drugs in LMICs. Lancet Lond Engl. 2018;392:714-6.

4. Fraser H, Mukandavire C, Martin NK, Hickman M, Cohen MS, Miller WC, et al. HIV treatment as prevention among people who inject drugs - a re-evaluation of the evidence. Int J Epidemiol. 2017;46:466-78.

5. Mehta SH, Lucas GM, Solomon S, Srikrishnan AK, McFall AM, Dhingra N, et al. HIV care continuum among men who have sex with men and persons who inject drugs in India: barriers to successful engagement. Clin Infect Dis Off Publ Infect Dis Soc Am. 2015;61:1732-41. 
6. Smith LR, Patterson TL, Magis-Rodriguez C, Ojeda VD, Burgos JL, Rojas SA, et al. Engagement in the HIV Care Continuum among Key Populations in Tijuana, Mexico. AIDS Behav. 2016;20:1017-25.

7. Joseph B, Wood E, Hayashi K, Kerr T, Barrios R, Parashar S, et al. Factors associated with initiation of antiretroviral therapy among HIV-positive people who use injection drugs in a Canadian setting. AIDS Lond Engl. 2016;30:925-32.

8. Kiriazova T, Lunze K, Raj A, Bushara N, Blokhina E, Krupitsky E, et al. "It is easier for me to shoot up": stigma, abandonment, and why HIV-positive drug users in Russia fail to link to HIV care. AIDS Care. 2017;29:559-63.

9. Heimer R, Usacheva N, Barbour R, Niccolai LM, Uusküla A, Levina OS. Engagement in HIV care and its correlates among people who inject drugs in St Petersburg, Russian Federation and Kohtla-Järve, Estonia. Addict Abingdon Engl. 2017;112:1421-31.

10. UNAIDS. 90-90-90: treatment for all. https://www.unaids.org/en/resources/909090. Accessed 5 Jul 2019.

11. Abdul-Quader AS, Baughman AL, Hladik W. Estimating the size of key populations: current status and future possibilities. Curr Opin HIV AIDS. 2014;9:107-14.

12. MacCarthy S, Hoffmann M, Ferguson L, Nunn A, Irvin R, Bangsberg D, et al. The HIV care cascade: models, measures and moving forward. J Int AIDS Soc. 2015;18:19395.

13. WHO | Cascade data use manual: to identify gaps in HIV and health services for programme improvement. WHO. http://www.who.int/hiv/pub/toolkits/hiv-cascade-data-use-manual/en/. Accessed 16 Jul 2019.

14. Islam MM, Topp L, Iversen J, Day C, Conigrave KM, Maher L. Healthcare utilisation and disclosure of injecting drug use among clients of Australia's needle and syringe programs. Aust N Z J Public Health. 2013;37:148-54.

15. Hladik W, Benech I, Bateganya M, Hakim AJ. The utility of population-based surveys to describe the continuum of HIV services for key and general populations. Int J STD AIDS. 2016;27:5-12.

16. Des Jarlais DC, Kerr T, Carrieri P, Feelemyer J, Arasteh K. HIV infection among persons who inject drugs: ending old epidemics and addressing new outbreaks. AIDS Lond Engl. 2016;30:815-26.

17. Panhard $X$, Legrand $M$, Taburet A-M, Diquet $B$, Goujard $C$, Mentré $F$, et al. Population pharmacokinetic analysis of lamivudine, stavudine and zidovudine in controlled HIV-infected patients on HAART. Eur J Clin Pharmacol. 2007;63:1019-29.

18. WHO | Consolidated guidelines on the use of antiretroviral drugs for treating and preventing HIV infection. WHO. https://www.who.int/hiv/pub/guidelines/arv2013/en/. Accessed 5 Jul 2019.

19. hiv_metrics.pdf. http://www.wpro.who.int/hiv/hiv_metrics.pdf. Accessed 3 Jan 2019.

20. Mooney AC, Campbell CK, Ratlhagana M-J, Grignon JS, Mazibuko S, Agnew E, et al. Beyond Social Desirability Bias: Investigating Inconsistencies in Self-Reported HIV Testing and Treatment Behaviors Among HIV-Positive Adults in North West Province, South Africa. AIDS Behav. 2018;22:2368-79. 
21. Gandhi M, Bacchetti P, Rodrigues WC, Spinelli M, Koss CA, Drain PK, et al. Development and Validation of an Immunoassay for Tenofovir in Urine as a Real-Time Metric of Antiretroviral Adherence. EClinicalMedicine. 2018;2-3:22-8.

22. Spinelli MA, Glidden DV, Rodrigues WC, Wang G, Vincent M, Okochi H, et al. Low tenofovir level in urine by a novel immunoassay is associated with seroconversion in a preexposure prophylaxis demonstration project. AIDS Lond Engl. 2019;33:867-72.

23. Gandhi M, Bacchetti P, Spinelli MA, Okochi H, Baeten JM, Siriprakaisil O, et al. Brief Report: Validation of a Urine Tenofovir Immunoassay for Adherence Monitoring to PrEP and ART and Establishing the Cutoff for a Point-of-Care Test. J Acquir Immune Defic Syndr 1999. 2019;81:72-7.

24. Latkin CA, Vlahov D. Socially desirable response tendency as a correlate of accuracy of self-reported HIV serostatus for HIV seropositive injection drug users. Addict Abingdon Engl. 1998;93:1191-7.

25. Latkin CA, Mai NVT, Ha TV, Sripaipan T, Zelaya C, Le Minh N, et al. Social Desirability Response Bias and Other Factors That May Influence Self-Reports of Substance Use and HIV Risk Behaviors: A Qualitative Study of Drug Users in Vietnam. AIDS Educ Prev Off Publ Int Soc AIDS Educ. 2016;28:417-25.

26. Rohr JK, Xavier Gómez-Olivé F, Rosenberg M, Manne-Goehler J, Geldsetzer P, Wagner RG, et al. Performance of self-reported HIV status in determining true HIV status among older adults in rural South Africa: a validation study. J Int AIDS Soc. 2017;20:21691.

\section{Tables}

Table 1 


\begin{tabular}{|c|c|c|c|}
\hline & $\begin{array}{l}\text { HIV-population } \\
\qquad n=451\end{array}$ & $\begin{array}{c}\text { HIV+ } \\
\text { population } \\
n=150\end{array}$ & $\begin{array}{c}P \\
\text { value }\end{array}$ \\
\hline Age, median[IQR] & $35[29 ; 43]$ & $37[33 ; 41]$ & 0.047 \\
\hline Male distribution, $\mathrm{n}(\%)$ & $411(91.0)$ & 129(86.0) & 0.132 \\
\hline Education level, $n(\%)$ & & & 0.057 \\
\hline$\S$ Never been to school & $3(0.7)^{+}$ & $3(2.0)$ & \\
\hline$\S$ Grade 1 to 5 & $41(9.2)$ & $22(14.7)$ & \\
\hline$\S$ Grade 6 to 9 & $201(45.0)$ & $73(48.7)$ & \\
\hline$\S$ Grade 10 to 12 & $187(42)$ & $47(31.3)$ & \\
\hline$\S$ Superior to grade 12 & $15(3.4)$ & $5(3.3)$ & \\
\hline Marital status, $\mathrm{n}(\%)$ & & & 0.072 \\
\hline - Divorced & $118(26.0)$ & $43(28.7)$ & \\
\hline - Married & $158(32.0)$ & $35(23.3)$ & \\
\hline - Live in couple & $7(1.6)$ & $3(2.0)$ & \\
\hline - Single & $161(36.0)$ & $65(43.3)$ & \\
\hline - Widow & $7(1.6)$ & $4(2.7)$ & \\
\hline Monthly incomes, n(\%) & & & 0.349 \\
\hline$<=3,000,000$ VND & $191(42)$ & $56(37.3)$ & \\
\hline$] 3,000,000 ; 5,000,000]$ VND & $158(35)$ & $50(33.3)$ & \\
\hline$>5,000,000$ VND] & 102(23) & $44(29.4)$ & \\
\hline Having at least one child, $n(\%)$ & $275(61.0)$ & $66(44.0)$ & $<0.001$ \\
\hline Hold an city registration card, $\mathrm{n}(\%)$ & $417(92.0)$ & 136(90.7) & 0.482 \\
\hline Hold a health insurance card, $n(\%)$ & 74(16) & $31(20.7)$ & 0.234 \\
\hline Having illegal incomes, $\mathrm{n}(\%)$ & 104(23.0) & $48(32.0)$ & 0.029 \\
\hline Having been arrested, $\mathrm{n}(\%)$ & $287(64.7)$ & 102(68.0) & 0.332 \\
\hline Having been jailed for more than 24 hours, & 143(32.3) & $63(42.0)$ & 0.021 \\
\hline
\end{tabular}


+4 missing data

Table 2 : Determinants for misreporting

\begin{tabular}{|c|c|c|c|}
\hline & $\begin{array}{l}\text { Well-reporting participants, } \\
\mathrm{n}=85\end{array}$ & $\begin{array}{l}\text { Misreporting participants, } \\
n=27\end{array}$ & $\begin{array}{l}\mathrm{p}- \\
\text { value }\end{array}$ \\
\hline Age, median[IQR]) & $37[33 ; 41]$ & $35[32 ; 43]$ & 0.63 \\
\hline Male, $n(\%)$ & $69(81.2)$ & $25(92.6)$ & 0.23 \\
\hline $\begin{array}{l}\text { Marital status, } \mathrm{n}(\%) \\
\S \text { in couple/maried } \\
\S \\
\text { single/widow/divor } \\
\text { ced }\end{array}$ & $\begin{array}{l}18(21.2) \\
67(78.8)\end{array}$ & $\begin{array}{c}9(33.3) \\
18(66.7)\end{array}$ & 0.20 \\
\hline $\begin{array}{l}\text { Education level, } \mathrm{n}(\%) \\
\S \text { Never been to school } \\
\S \text { Grade } 1 \text { to } 5 \\
\S \text { Grade } 6 \text { to } 9 \\
\S \text { Grade } 10 \text { to } 12 \\
\S \text { Superior to grade } 12\end{array}$ & $\begin{array}{c}2(2.6) \\
14(16.5) \\
41(48.2) \\
25(29.4) \\
3(3.5)\end{array}$ & $\begin{array}{c}0(0.0) \\
4(14.8) \\
13(48.2) \\
9(33.3) \\
1(3.7)\end{array}$ & 0.99 \\
\hline $\begin{array}{l}\text { CD4 cell count, } n(\%) \\
\S<=350\end{array}$ & $28(32.9)$ & 10(37.0) & 0.70 \\
\hline $\begin{array}{l}\text { HIV viral load, } n(\%) \\
\S<1,000 \text { copies/mL }\end{array}$ & $55(64.7)$ & $17(63.0)$ & 0.87 \\
\hline
\end{tabular}

* 2 missing data

Figures 


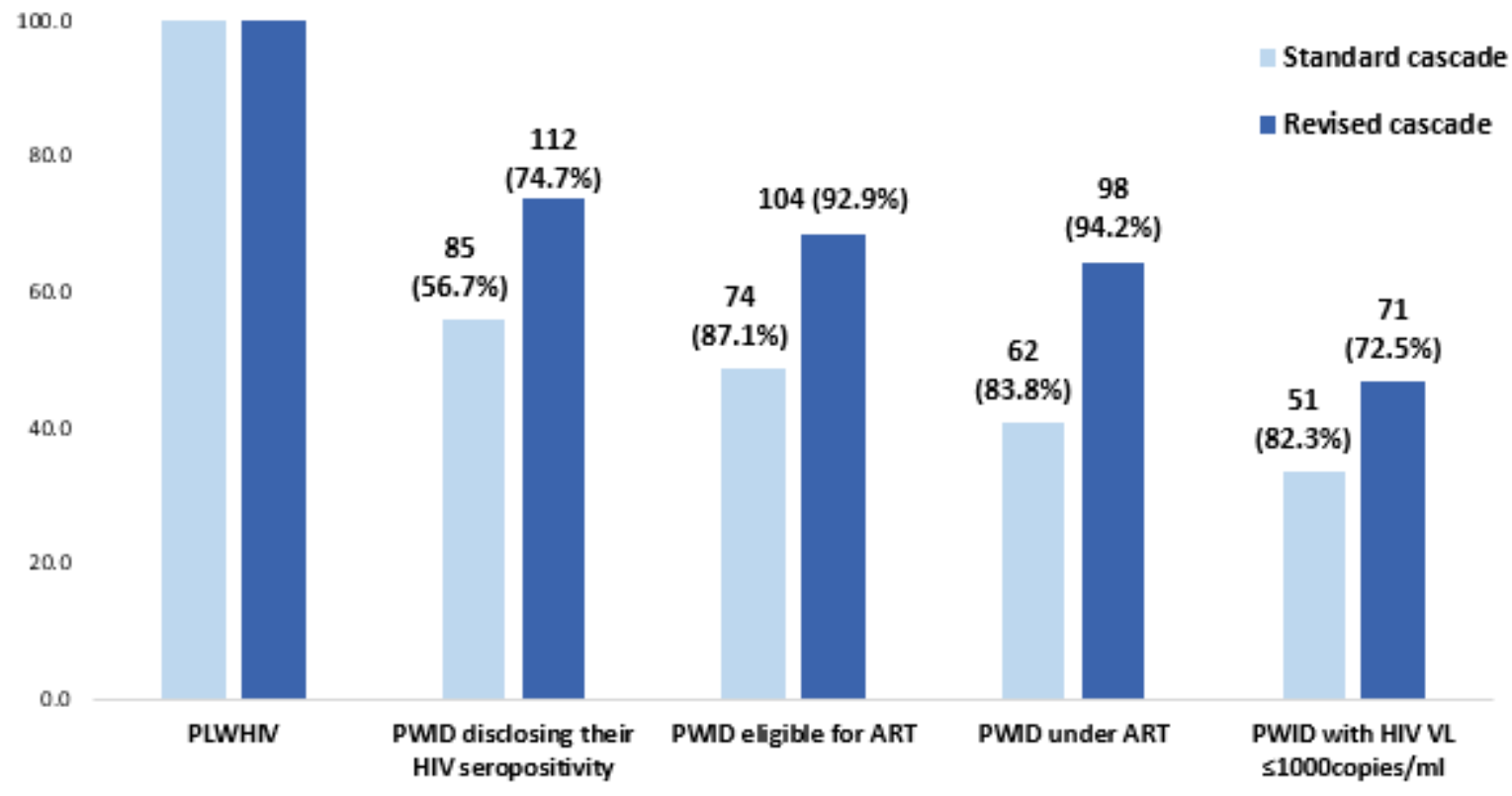

\section{Figure 1}

Standard and improved cascade of care among PWID in Hai Phong 